\title{
AFTER COP21: Politics of Decarbonisation
}

\author{
Jan-Erik Lane
}

Fellow with Public Policy Institute in Belgrade, Geneva

\begin{abstract}
Global governance has arrived at a spectacular decisions or set of objectives, namely the decarbonisation of the world economy in three major steps during this century. Talking is cheap, but doing and accomplishing is hard, taight American policy analyst Aaron Wildavsky. Decarbonisation is a gigantic enterprise, involving the stop of increases in CO2:s, a 40 per cent reduction up to 2030 and perhaps a total (?) decarbonisation around 2075. Maybe this agreement, COP21, will calm some environmentalists, but it may just be a figment of their imagination. CO2:s keep increasing daily, we are told by Earth's C02 Page. Yet, cutting GHG:s implies changing energy consumption that is driving economic growth. The COP21 runs into a dilemma: either conventional energy consumption for growth or massive energy changes that will reduce economic development.
\end{abstract}

Keywords: COP21, GHG:s, CO2:s, economic development or growth, energy-emissions link, energy-GDP links, bio-mass, country predicaments.

\section{INTRODUCTION}

Let me start by accepting the overall emphasis of the natural scientists' community upon the power of energy to regulate our immense universe, but look at this from a social scientist's point of view. If matter is basically energy, then there is an unimaginable amount of it. But the societies in the Planet Earth do not have enough of it. Thus, nations plan to augment their energy consumption, but it is the major source of anthropogenic emissions of GHG:s that could threaten the viability of mankind. If energy is indestructible, as thermodynamics teaches us, then burning a huge amount of fossil fuel energy and forests (charcoal) in a short time period must heat the atmosphere. Thus, we arrive at the energy-emission conundrum: How to stop global warming while continuing the struggle against poverty and in favour of better living conditions, especially in the Third World?

\section{THE ENERGY SitUATION}

Energy is the capacity to do work. Lacking energy, no social system can operate, not even the family. The daily use of energy is almost astromical on a small Planet Earth, and it has had a trend of steady increases year by year. The governments of the states of the world have obliged the change the prevailing energy pattern profoundly in a short time period of a few decades.

Not only may all forms of energy be measured, but all these measures are translatable into each other - a major scientific achievement. One may employ some standard sources on energy consumption and what is immediately obvious is the huge numbers involved - see Table 1.

Table1. Energy Consumption 2015 (Million Tonnes of Oil Equivalent)

\begin{tabular}{|l|l|l|}
\hline & Total & $\%$ \\
\hline Fossil fuels & 11306,4 & 86,0 \\
\hline Oil & 4331,3 & 32,9 \\
\hline Natural Gas & 3135,2 & 23,8 \\
\hline Coal & 3839,9 & 29,2 \\
\hline Renewables & 1257,8 & 9,6 \\
\hline Hydroelectric & 892,9 & 6,8 \\
\hline Others & 364,9 & 2,8 \\
\hline Nuclear power & 583,1 & 4,4 \\
\hline & 13147,3 & 100,0 \\
\hline
\end{tabular}

Source: BP Statistical Review of World Energy 2016 
Examining Figure 1, one understands the size of the task of the decarbonisation policy effort. Complete decarbonisation would mean the elimination of the energy consumption of fossil fuels and traditional renewables. This is a herculean task, impossible simply. But the mix of energy usage will change during this century towards more of carbon neutral energy sources, but all the stylised energy projections provide fossil fuels with prominent share of energy markets.

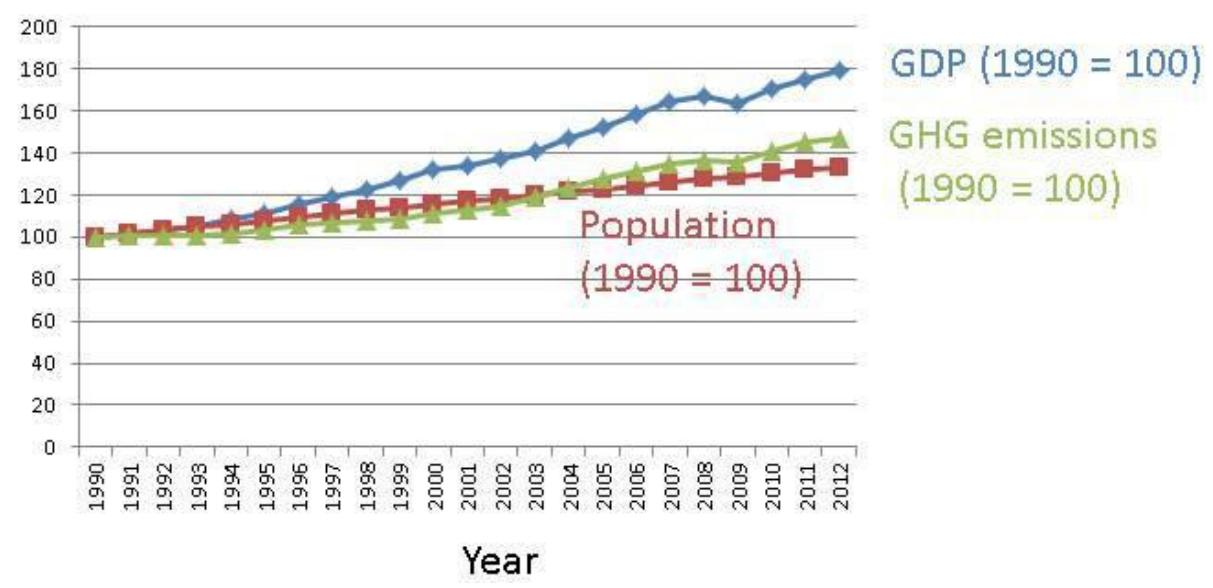

Figure1. The Global Scene

COP21 management can do nothing about population growth increasing the CO2:s directly and indirectly, but it may attempt to change energy consumption so that the link between GDP and $\mathrm{GHG}(\mathrm{CO} 2)$ is broken (Figure 2).

LN

(Total GHG Emissions / Kg) $\mathrm{CO} 2$ equivalent

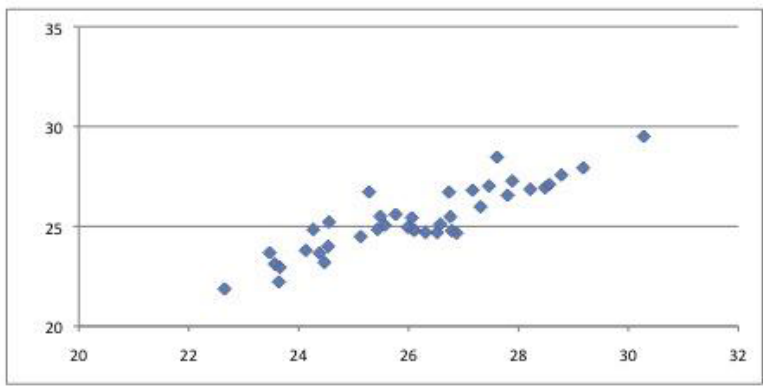

LN ( GDP / USD) (constant value 2005)

Figure2. GDP-GHC Link Globally

However, given the link in Figure 2, COP21 management cannot simply recommend that economic output be cut back - Sach's sustainable economy. Decarbonisation is to be maximised, given the constraint that economic growth is NOT undermined. But the energy needs of human social systems just keep augmenting (Figure 3).

GDP vs. Energy usage per capita $1990-2014$

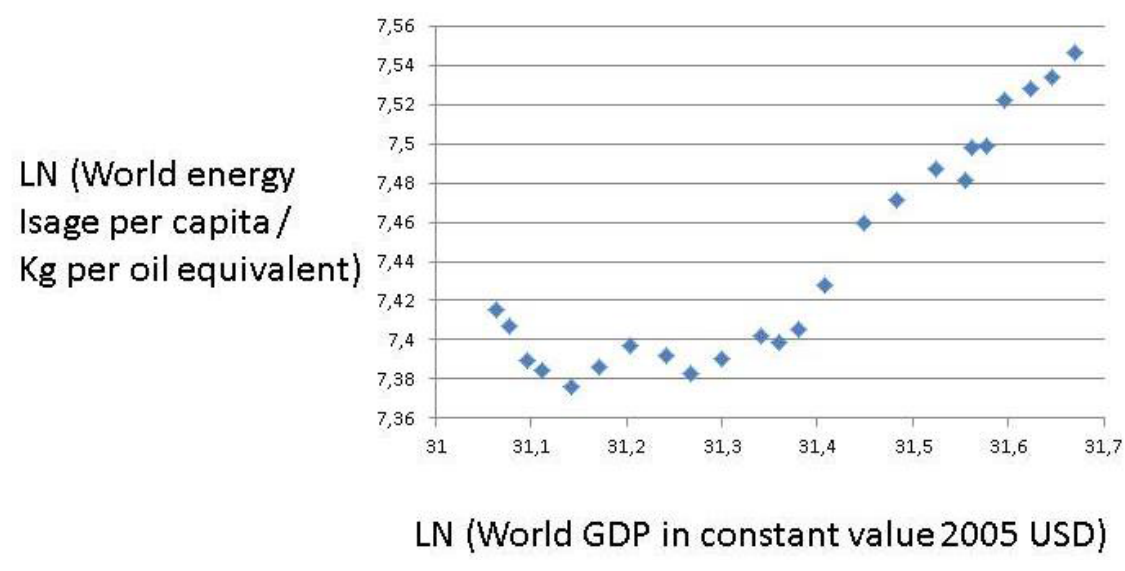

Figure3. Economic Development and Energy Per Person 
Thus, the «noyeau» : Change energy pattern ! But it can only be done by each country in the world. Let us distinguish the promising cases from the not so promising ones, i.e. with regard to the possibility of rational management of COP21 goals. Where is goal achievement likely?

\section{Global WARMing}

The global warming process is already on and proceeds seemingly unstoppably, involving inter alia larger climate swings, deforestation, desertification, ocean acidification and rising sea levels. One does not really know whether it is an irreversible transformation of Planet Earth, or where it could be stopped: $+1,5,+2,+2,7,+4,+6$, or would end in a global catastrophe. We look at the last two decades when the debate about climate change really got momentum as the evidence has multiplied about a dangerous process of global warming.

Two sets of data are useful here. On the hand, the country GHG emissions have been taken from two sources: World Resources Institute, EU Joint Research Centre Emission and UN Framework Convention on Climate Change. On the other hand, country GDP numbers are available in the following sources: World Bank and OECD. Combining these data sources and transforming the enormous figures by the LN allows us to put up emissions' growth against GDP growth for the last 20 years. This allows for the identification of the standard link between economic development and emissions, while also finding a few countries that have succeeded to halt if not also reverse the trend towards more and more emissions. The emission of GHG:s and the rates of GDP development have one element in common, namely the use of energy. Countries that have not succeeded in halting emissions are extremely reliant upon fossil fuels, especially coal. Yet, the use of certain renewables does not always lead to reductions in aggregate country emissions.

The energy-environment question lies at the core of the global warming problematic, and it concerns how vital human activities require sources of energy. Appendix 1 displays these energy sources and their relative weights. No economic activity or development would be feasible without energy, its production and consumption. Energy use shows up everywhere in our social and economic systems. But they result almost always in the emission of GHG, especially CO2.

Globally speaking, more than 80 per cent of the energy consumed daily is derived from the burning of fossil fuels. How fast can this be changed and what could be the economic costs of decarbonisation? Countries can attempt to meet their obligations in the COP21 Agreement by decarbonisation, lower economic growth or more energy efficiency. New technology and innovations will be crucial, not only in small scale endeavours but used massively.

\section{DECARBONISATION AND ECONOMIC DEVELOPMENT}

Sachs has launched a coherent call for the world to move towards sustainable development, based on decarbonisation of the energy systems of countries (http://jeffsachs.org/2015/08/sustainabledevelopment-for-humanitys-future/). He has correctly emphasized the close link between economic development or growth and the massive use of fossil fuels as energy sources during the last 20 years, resulting in the enormous expansion of GHG emissions. But will countries really opt for a sustainable economy, given all the demands for more of energy resources?

So the key question in relation to COP21 becomes the following: Given this close link between GDP and energy consumption on the one hand and the equally close link between energy provision or use and the emission of GHG:s or CO2:s, how can the countries of the world achieve decarbonisation without hampering economic development or growth? What is the country link between GDP and GHG emissions? It depends upon the nation in question!. Let us make a short survey of country predicaments regarding:

$<$ GHG-GDP link, energy mix>, as a model of the prospects for decarbonisation.

\section{EMERGING ECONOMIES}

One may find that the emissions of GHG:s follows economic development closely in many countries. The basic explanation is population growth and GDP growth - more people and higher life style demands. Take the case of China, whose emissions are the largest in the world, totally speaking (Figure 4). 


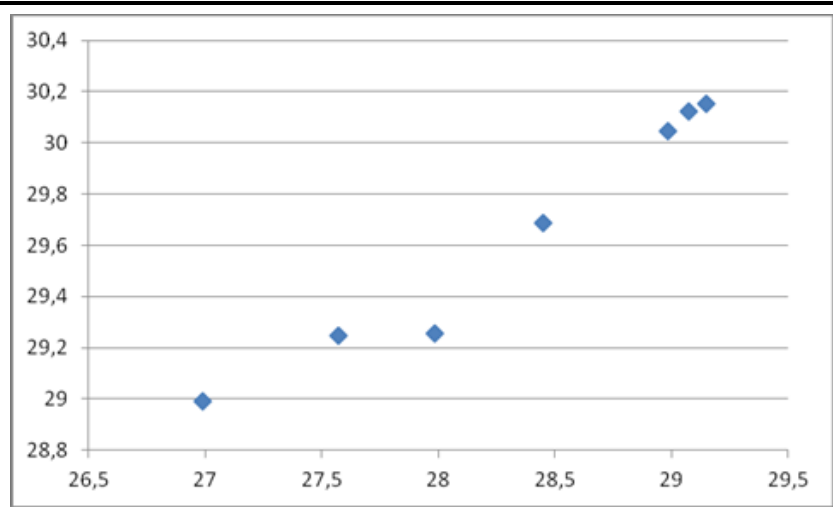

Figure4. CHINA: LN (GHG / Kg CO2 eq and LN (GDP/Constant Value 2005 USD)

Note: $\mathrm{GHG}=\mathrm{y}$-axis, GDP $=\mathrm{x}$-axis

The sharp increase in GHG:s in China reflects not only the immensely rapid industrialization and urbanization of the last 30 years, but also its problematic energy mix (Figure 5).

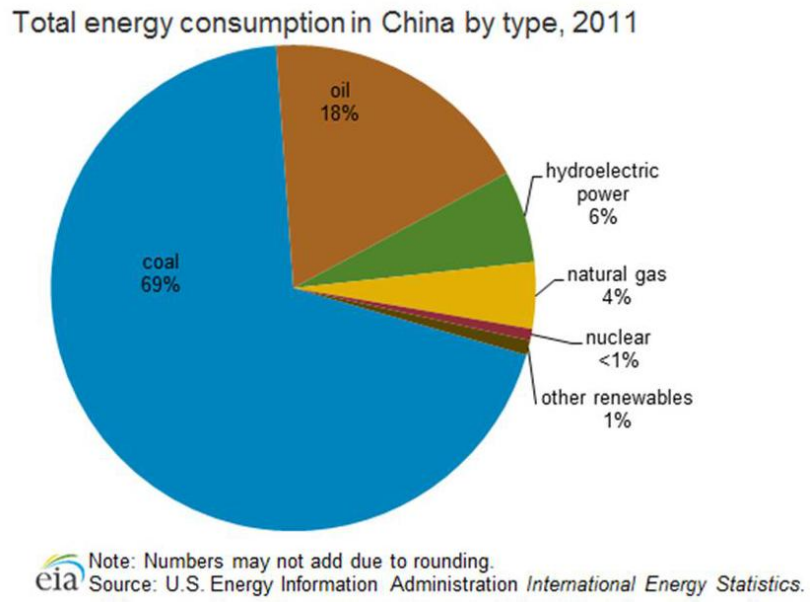

Figure5

Almost 70 per cent of the energy consumption comes from the burning of coal with an additional 20 per cent from other fossil fuels. The role of nuclear, hydro and other renewable energy sources is very small indeed. This makes China very vulnerable to demands for cutting GHG emissions: other energy sources or massive installation of highly improved filters?

It should be pointed out that several small countries have much higher emissions per capita than China. This raises the enormously difficult problematic of fair cuts of emissions. Should the largest polluters per capita cut most or the biggest aggregate polluters? At COP21 this issue was resolved by the creation of a super fund to assist energy transition and environment protection in developing counties, as proposed by economist Stern (2007)

India will certainly appeal to the same problematic, namely per capita or aggregate emissions. The country is even more negative than China to cut GHG emissions, as it is in an earlier stage of industrialization and urbanization. Figure 6 shows the close connection between emissions and GDP for this giant nation.

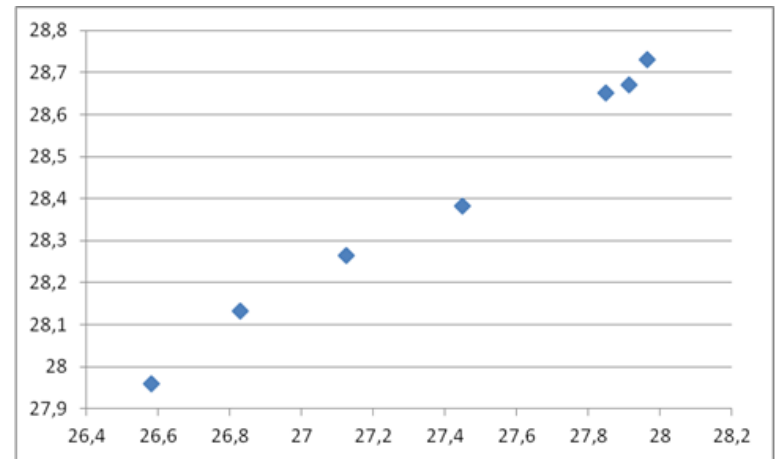

Figure6. INDIA: $L N$ (GHG / Kg CO2 eq and LN (GDP/Constant Value 2005 USD)

Note: $G H G=y$-axis, $G D P=x$-axis 
India needs cheap energy for its industries, transportation and heating (Figure 6) as well as electrification. From where will it come? India has water power and nuclear energy, but relies most upon coal, oil and gas as power source. It has strong ambitions for the future expansion of energy, but how is it to be generated, the world asks. India actually has one of the smallest numbers for energy per capita, although it produces much energy totally. Figure 7 shows its energy mix where renewables play a bigger role than in China.

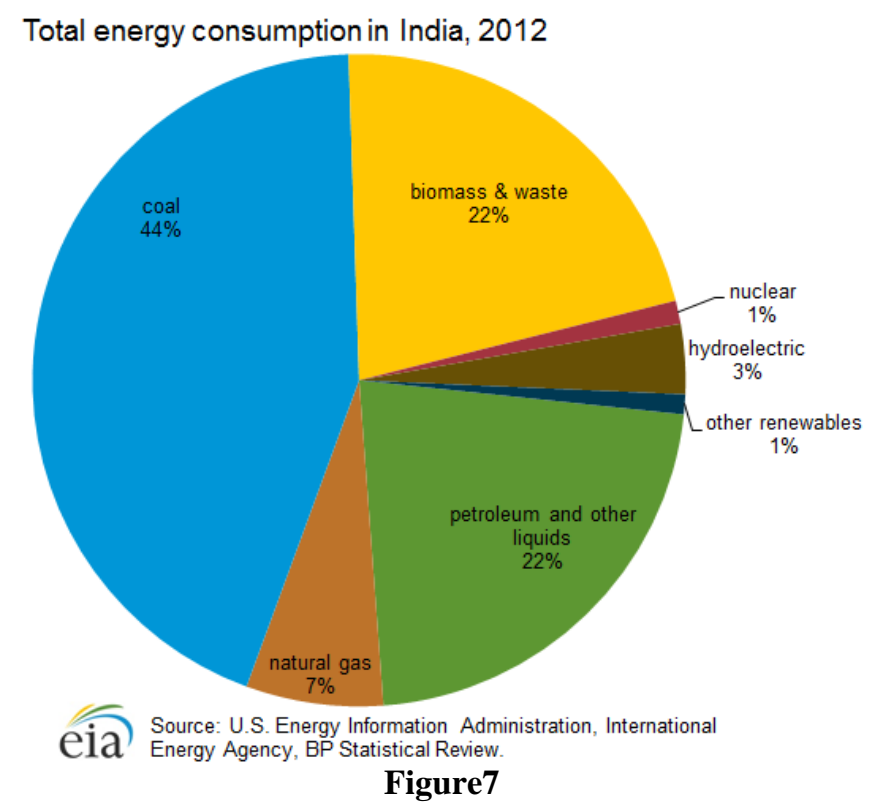

India needs especially electricity, as 300 million inhabitants lack access to it. The country is heavily dependent upon fossil fuels (70 per cent), although to a less extent than China. Electricity can be generated by hydro power and nuclear power, both of which India employs. Yet, global warming reduces the capacity of hydro power and nuclear power meets with political resistance. Interestingly, India uses much biomass and waste for electricity production, which does not always reduce GHG emissions. India's energy policy will be closely watched by other governments and NGO:s after 2018.

One may guess correctly that countries that try hard to "catch-up" will have increasing emissions. This was true of China and India. Let us look at three more examples, like e.g. giant Indonesia -now the fourth largest emitter of GHG:s in the world..

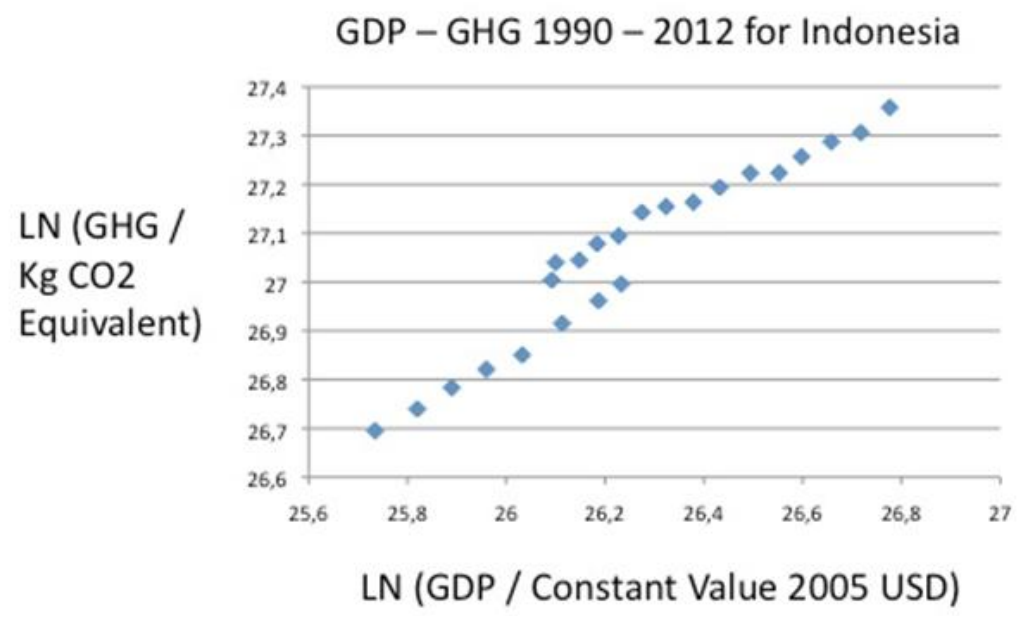

Figure8. INDONESIA: LN (GHG / Kg CO2 eq and LN (GDP/Constant Value 2005 USD)

Indonesia is a coming giant, both economically and sadly in terms of pollution. Figure 8 reminds of the upward trend for China and India. However, matters are even worse for Indonesia, as the burning of the rain forest on Kalimantan augments the GHG emissions very much. Figure 9 presents the energy mix for this huge country in terms of population and territory. 


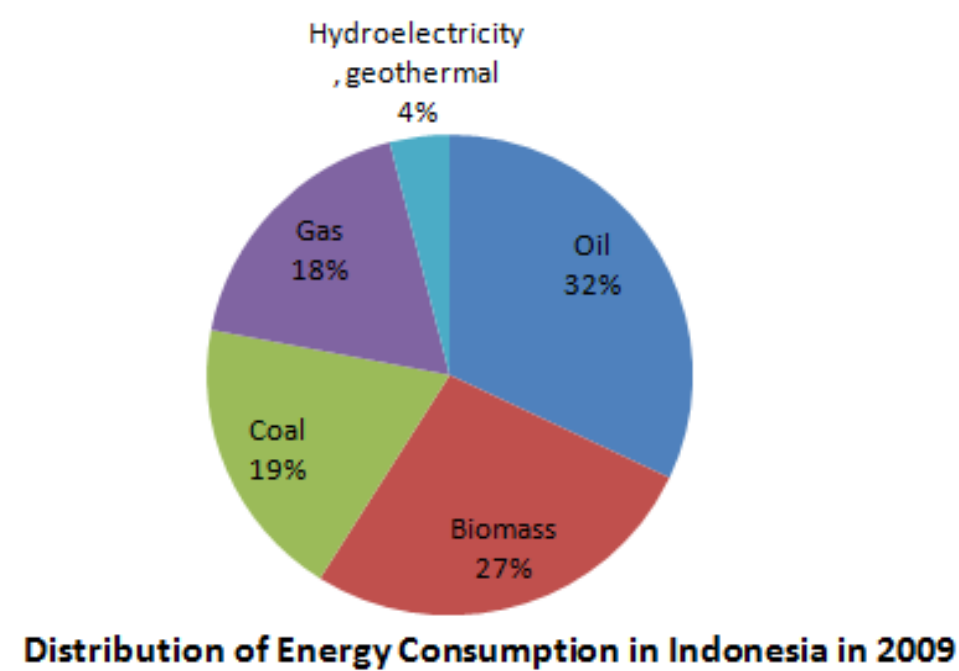

Figure9. (http://missrifka.com/energy-issue/recent-energy-status-in-indonesia.html)

Only 4 per cent comes from hydro power with 70 per cent from fossil fuels and the remaining 27 per cent from biomass, which alas also pollutes.

The same upward trend holds for another major developing country with huge population, namely Pakistan (Figure 10).

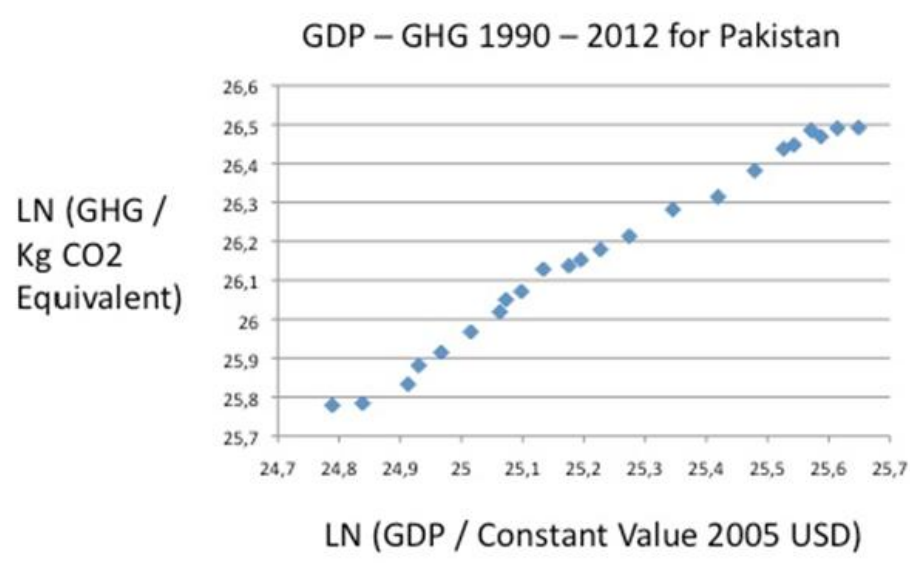

Figure10. PAKISTAN: LN (GHG / Kg CO2 eq and LN (GDP / Constant Value 2005 USD)

The amount of GHG emissions is high for Pakistan, viewed as aggregate. Pakistan is mainly reliant upon fossil fuels (Figure 11).

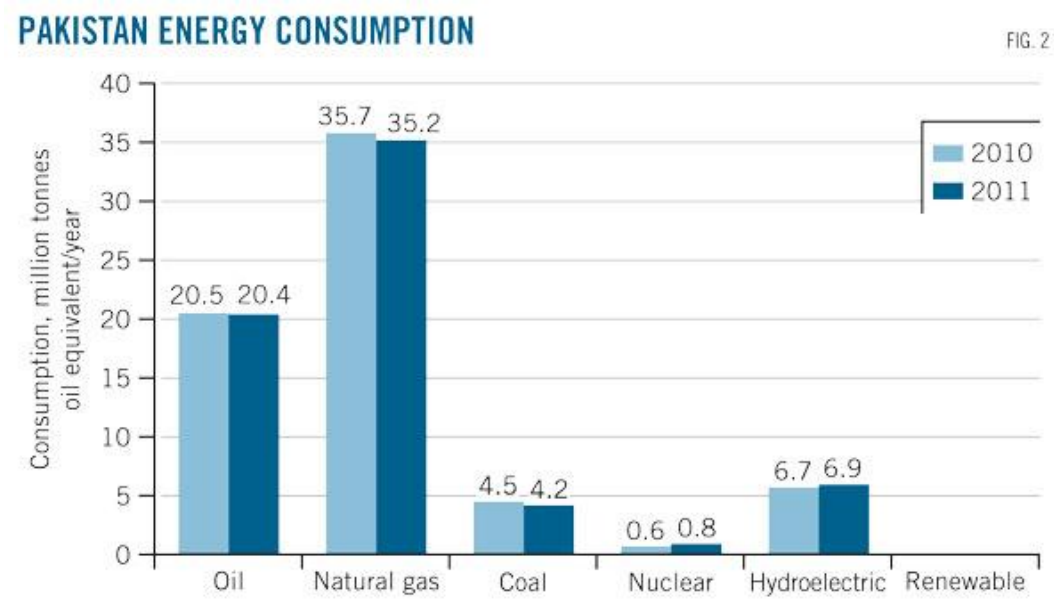

Figure11 
But Pakistan employs a considerable portion of hydropower - 13 per cent - and a minor portion of nuclear power. Looking at South Africa, it is the same trend constantly upwards.

Emissions are high, because South Africa uses a lot of coal to generate electricity (Figure 12). Decarbonisation will be difficult and costly.

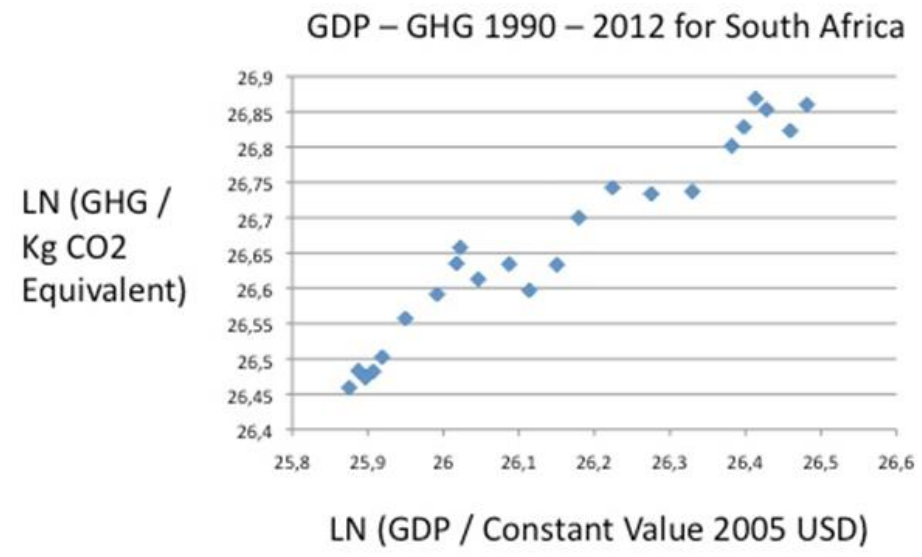

Figure12. SOUTH AFRICA: LN (GHG / Kg CO2 eq and LN (GDP / Constant Value 2005 USD)

The reliance upon coal in this large economy in Africa is stunningly high. No wonder that the RSA has started to look for shale oil and gas, but solar power stations would definitely be better for ecological reasons.

Figure 1. Total primary energy consumption in South Africa, 2013

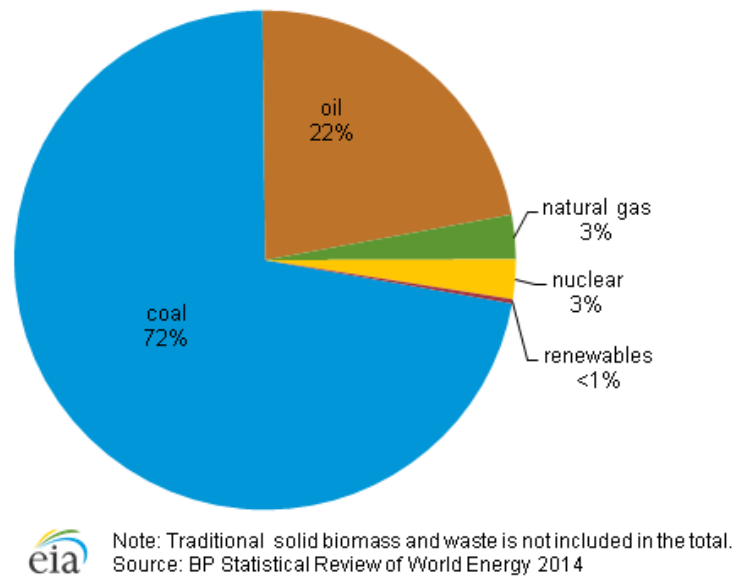

Figure13

Let us Look now at the ethanol country par preference: Brazil. Figure 14 shows a considerable drop in total emissions, but it is followed by huge increases that tend to flatten out.

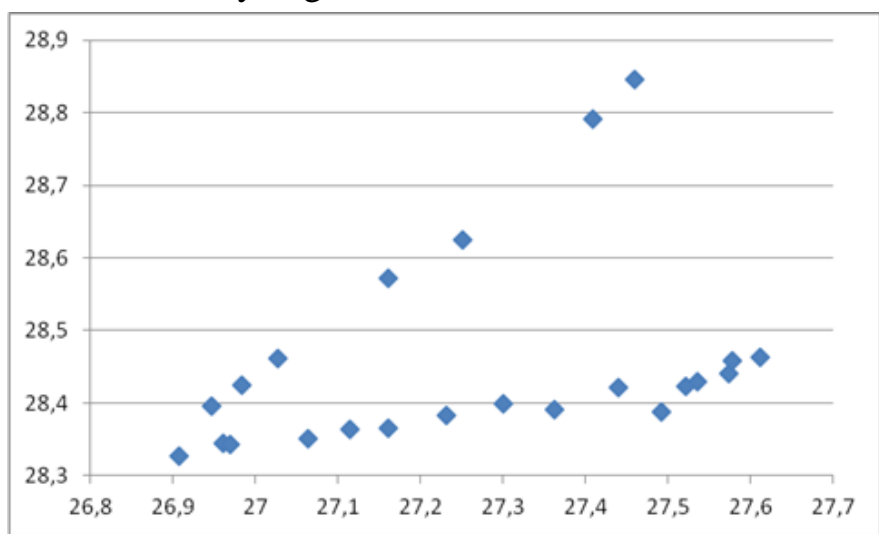

Figure14. BRAZIL: $L N(G H G$ / Kg CO2 eq and LN (GDP / Constant Value 2005 USD)

Note: $G H G=y$-axis, $G D P=x$-axis

Brazil employs the most biomass in the world, but the emissions stay at a high level, which is a reminder that renewables may also have GHG:s. One advantage for Brazil is the large component of hydro power, but the overall picture for the largest Latin American country is not wholly promising 
when it comes to the reduction of emissions. Global warming reduces the potential of hydro power water shortages, and Brazil has very little nuclear power (Figure 15).

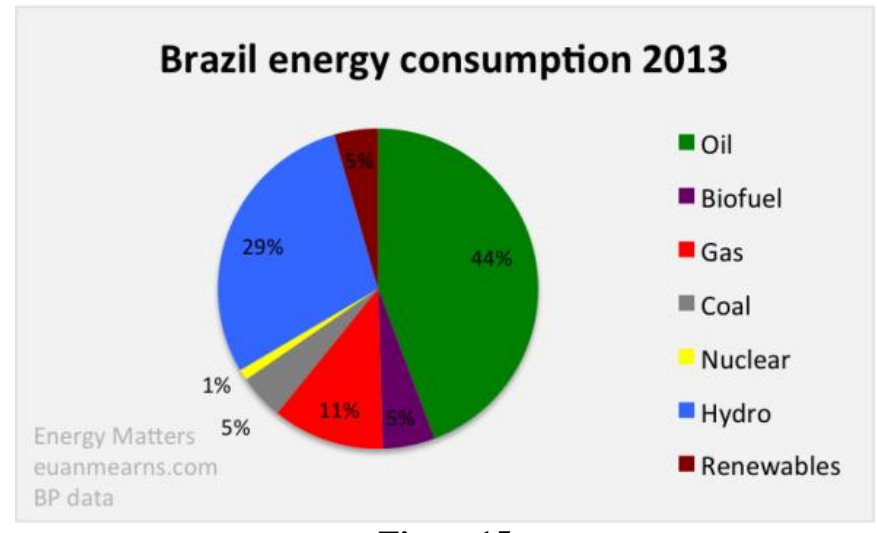

Figure15

\section{Summing UP}

The big emerging economies in the world are completely out of touch with the COP21 objectives. To fulfil them, they must change dramatically. But will they? Energy is crucial for their "catch-up" strategy in relation to the rich world, and to transform the basic features of energy consumption requires time and money. I am inclined to predict that some of these countries above will renege upon GOAL I (halting CO2 increases by 2020) and GOAL 2 (reduction of CO":s by 40 per cent up to 2030) in the COP21 project.

\section{MATURe ECONOMies}

The picture of a very close link between GDP and emission of GHG:s that is to be found with the giants in Asia does not necessarily hold for all countries. Let us look at a few countries where this link is weaker, starting with Canada that has halted the expansion of GHG:s (Figure 16).

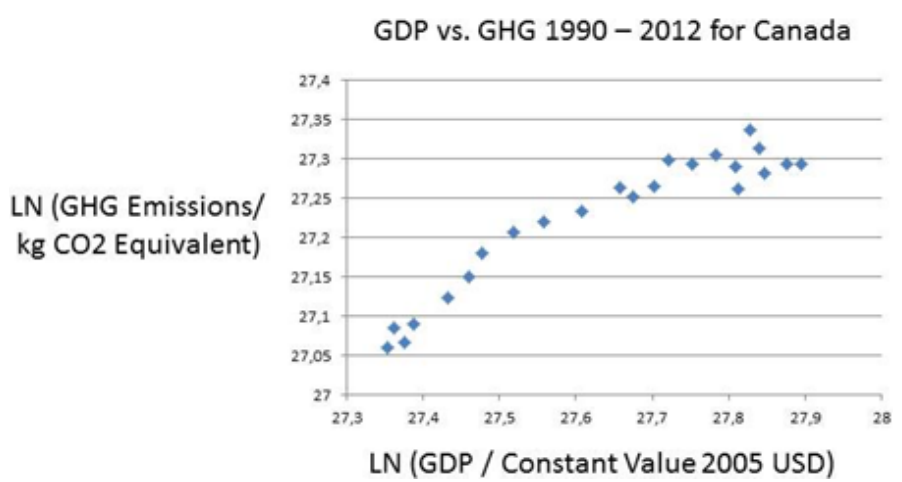

Figure16. CANADA: LN (GHG / Kg CO2 eq and LN (GDP / Constant Value 2005 USD)

Although Canada is a major emitter of GHG:s as well as one of the world's largest fossil fuel producer - oil sands, it had managed to stem the increase in emissions for the most recent years, i.e. halting the augmentation. Figure 17 may be invoked to explain this, showing a very mixed energy consumption pattern.

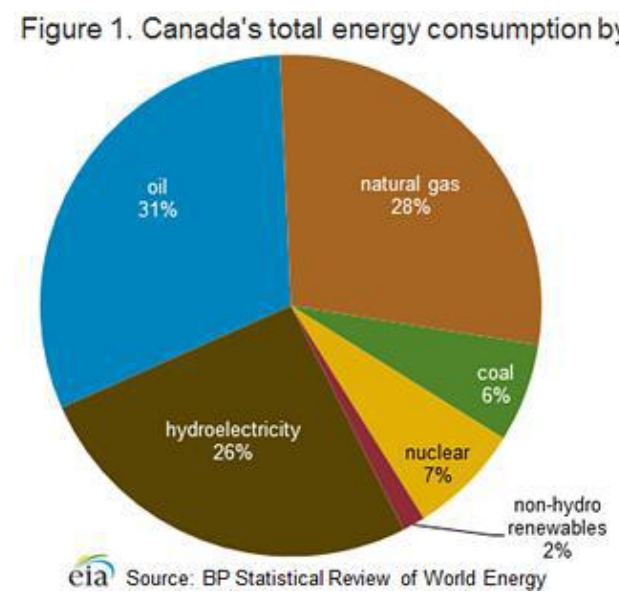

Figure17 
Canada has a strong advantage compared with for instance China and India in that it has access to lots of hydro power and natural gas. The burning of coal is as low as 12 per cent, but oil still makes up almost a third of energy consumption.

For most countries hold that their emission of GHG:s increases, as well as augments with the GDP. However, there are a few notable exceptions of decreases that are worth mentioning. We start with the US (Figure 18).

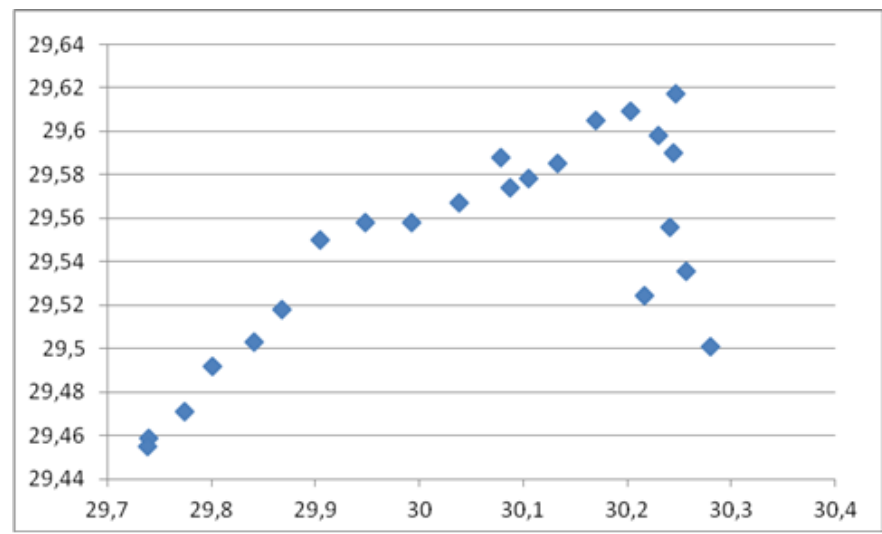

Figure18. USA: $L N$ (GHG / Kg CO2 eq and LN (GDP / Constant Value 2005 USD)

Note: $G H G=y$-axis, $G D P=x$-axis

Recently, the level of GHG emission has been reduced significantly in the US. It reflects no doubt the economic crisis that began 2007, but the US remains the second largest polluter in the world, reflecting that it cannot draw upon a mixed bag of energies (Figure 19). Per capita GHG:s is of course very high for the USA. As the economy now starts to accelerate, emissions are bound to go up again.

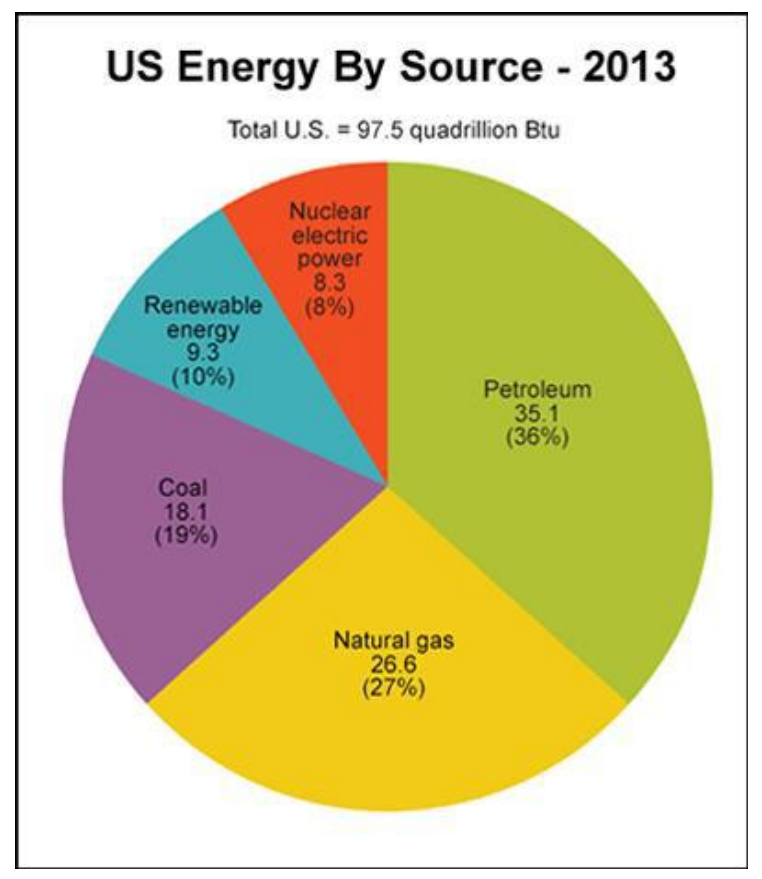

Figure19

The US is heavily dependent upon fossil fuels, or some 89 per cent comes there from. What is changing is the more and more of energy is produced within the US and no longer imported from outside - the shake oil and gas revolution. Further reduction of GHG:s will meet with firm resistance from the Republican House of Congress, which may oppose the COP21 Agreement. The advent of shale oil and gas has changed the entire energy markets, lowering the price of oil most substantially. This implies not only that there will be no Hubbert peak oil for the world, but also that switching to renewable energy source will be extremely expensive, relatively speaking.

Another interesting country is the largest EU economy, namely Germany. Figure 20 shows a marked decrease in GHG emissions. 


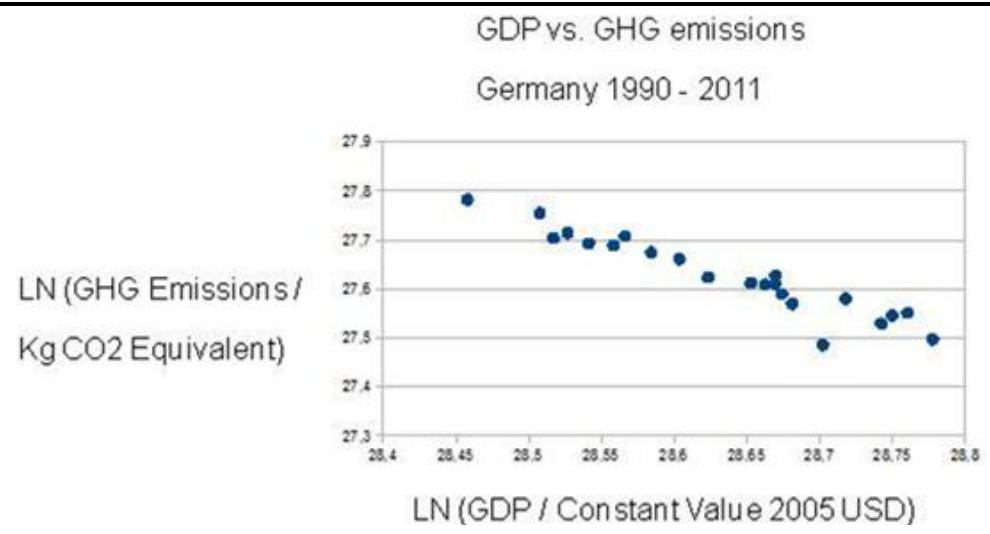

Figure20. GERMANY: LN (GHG / Kg CO2 eq and LN (GDP / Constant Value 2005 USD)

The German data shows a consistent decreasing trend, which is not to be found with many countries, if at all. How come this German exceptionalism? Germany needs massive amounts of energy, but it decided to phase out nuclear power. Can really the domestic employment of renewables satisfy this gigantic demand (Figure 21)?

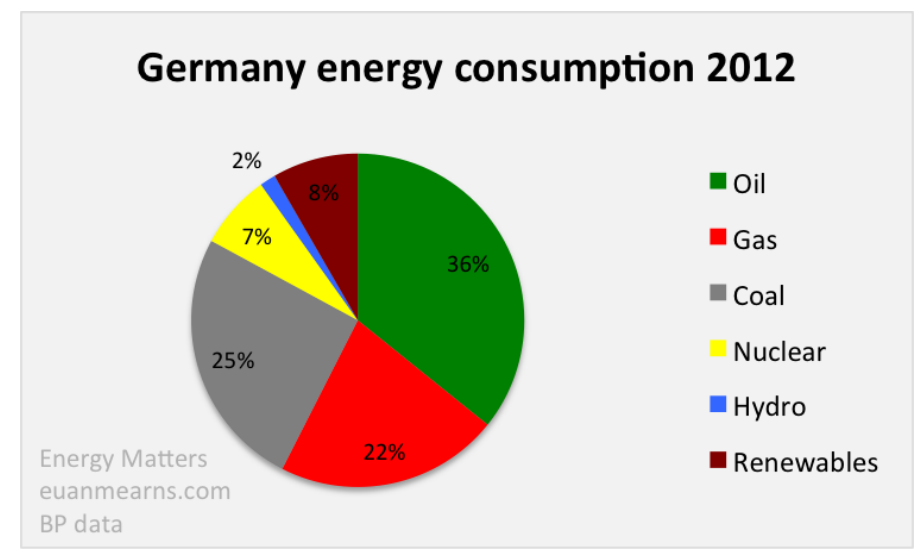

Figure21

It is true that nuclear power and renewables has made it possible for Germany to decrease its GHG:s, but the country is still dependent upon fossil fuels, especially coal and oil. What will happen with the nuclear power stations are phased out in 2022 is that most likely the GHG emissions will start going up again. To replace nuclear power with solar and wind power will be difficult to say the least. Already, Germany uses more coal from Columbia and gas from Russia.

Japan has a rather similar situation in that it will no longer rely much upon nuclear power. Its emissions have gone done recently, but seem to be on the rise again (Figure 22).

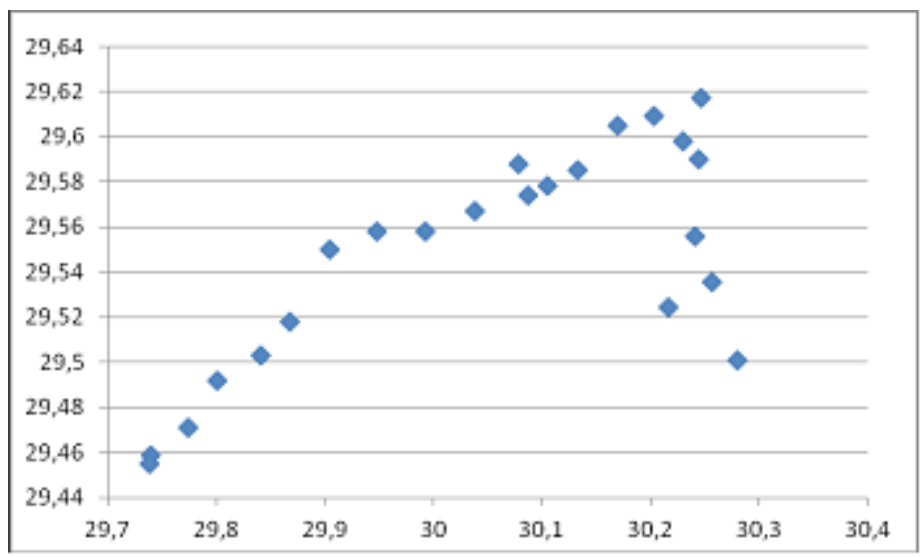

Figure22. JAPAN: LN (GHG / Kg CO2 eq and LN (GDP / Constant Value 2005 USD)

The decrease in emissions for Japan reflects the country's post-industrial developments. Production sites have been moved out of Japan with heavy investments in other Asian countries as well as the EU and the US. Yet, Japan will still need massive amounts of energy (Figure 23). After the Fukushima disaster, it operates only 1 nuclear power station. 


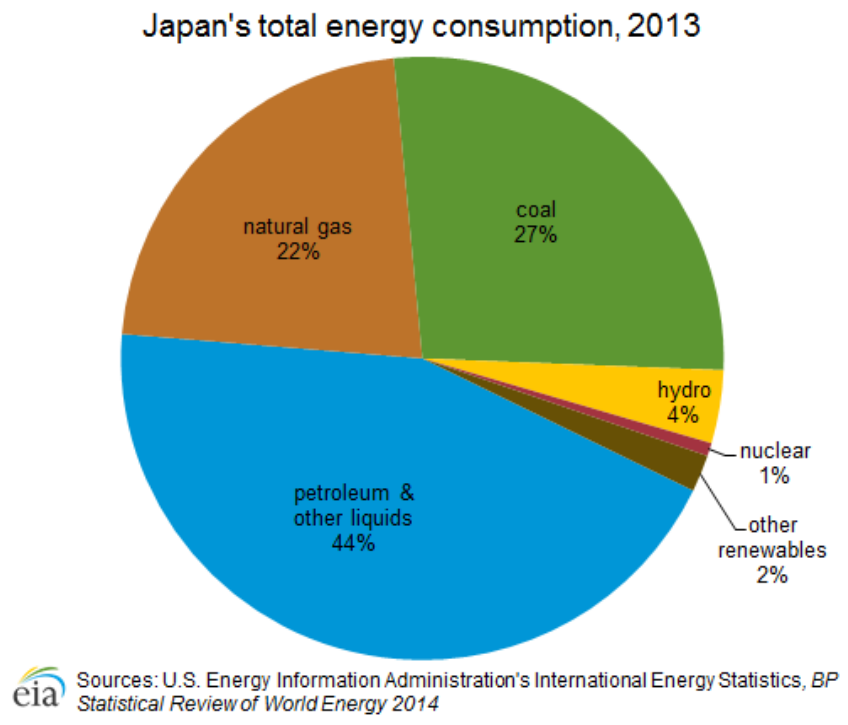

Figure23

As Figure 23 shows, Japan is very dependent upon fossil fuels for generating electricity and transportation, especially when nuclear power is no longer a major option with one nuclear power plant operating now in Japan.

However, a very close link between GDP and GHG is to be found in South Korea (Figure 24), which has 'caught up' in a stunning speed. Thus, one cannot be certain that a mature economy will run on lower energy input.

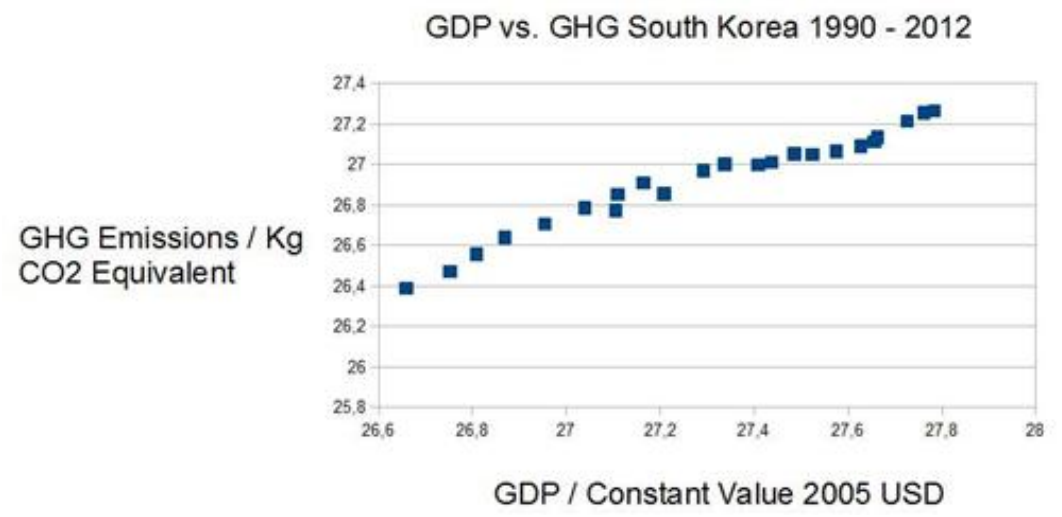

Figure24. SOUTH KOREA: LN (GHG / Kg CO2 eq and LN (GDP/Constant Value 2005 USD)

Lacking much hydro power, South Korea has turned to fossil fuels for energy purposes, almost up to 90 per cent (Figure 25).

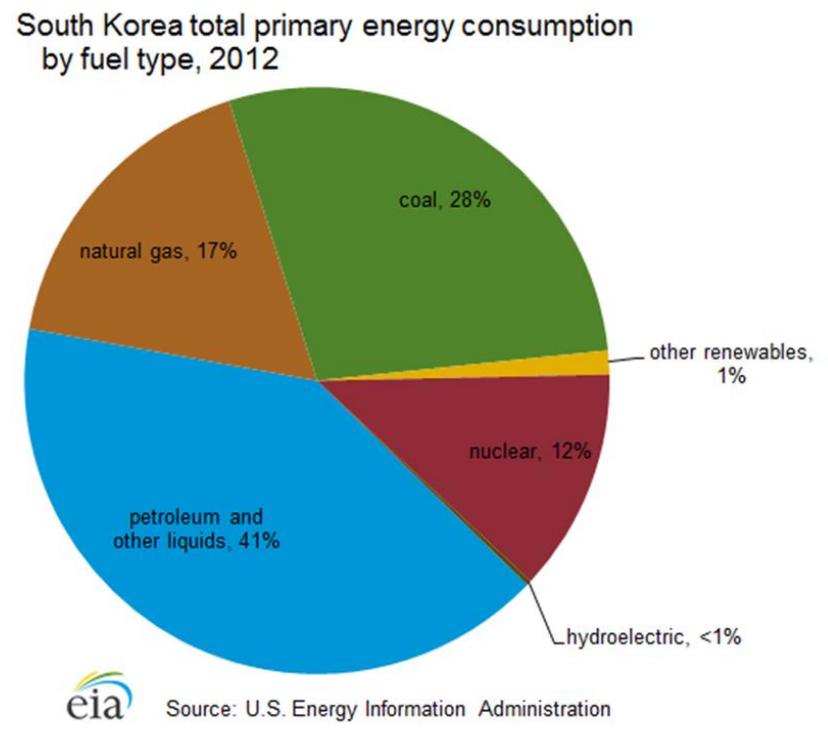

Figure25 
It differs from China only in the reliance upon nuclear power, where the country is a world leader in plant constructions. Reducing its GHG emissions, South Korea will have to rely more upon renewable energy sources, as well as reducing coal and oil for imported gas or LNGs.

The above three countries are giant polluters in terms of GHGs. China and South Korea uses mainly fossil fuels for energy consumption, whereas India also employs renewables and hydro power, lacking in the other two. Yet, the burning of renewables like biomass and waste for electricity generation also leads to GHG emissions. Only nuclear and hydro constitute emissions neutral energy.

Ideally, a country would wish to start reducing its emissions of GHG:s without any major impact upon the GDP. This would require a policy mix of promoting energy efficiency, moving towards the use of renewables massively and cutting back upon fossil fuels. I have found one country that fits these conditions - Sweden (Figure 26).

Interestingly, Sweden has embarked upon a steady trend towards emissions reduction, while still experiencing economic growth. The answer may lie in its pattern of energy consumption (Figure 26). Stunningly, GHG:s are no longer decreasing, while the atomic power programme has been shrunk.

\section{Swedish Energy Generation 2015}

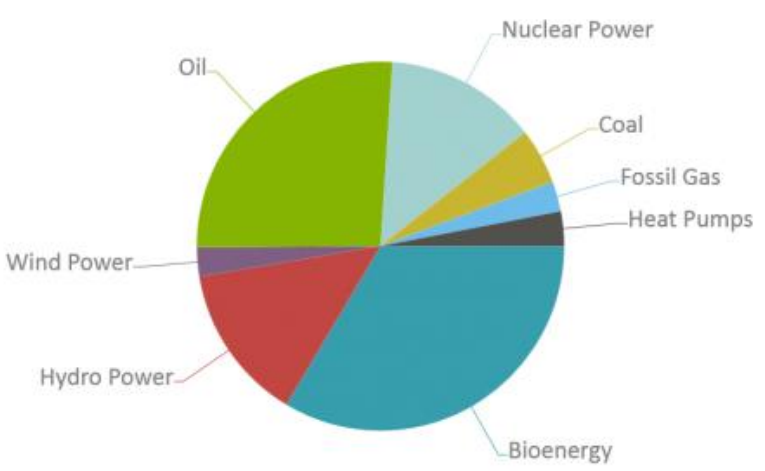

Figure26. Energy Consumption in Sweden 2015

\section{Summing Up}

We have found that several mature economies, except South Korea has begun the decarbonisation process, satisfying GOAL I. But they are far from achieving GOAL II. And GHG:s may reverse direction, starting to increase again, like in e.g. Sweden. Energy is the key. Can really wind and solar energy replace much of the fossil fuels? Environmentalists hoped that the world economy would stumble on a so-called Hubbert Peak, but the new shale oil and gas has changed everything. Nuclear power is no longer expanded in many countries, but on the contrary reduced. But the turn to bio-mass (wood waste, trash waste, peat, sawdust, manure, gas fills, residues from forestry and industry, etc) or bio-fuels like corn as well as to the massive exploitation with shale oil and gas may not be conducive to decarbonisation. It may even prevent the development of clean renewables or atomic power. Biomass and carbon neutrality is a much controversially debated topic, where it is not entirely clear that bio-mass is superior.

\section{The So-Called Green StateS}

Some countries applaud themselves for a positive energy policy, i.e. a policy that leads to decreases in emissions. But is it really true? Look first at Singapore in Figure 27.

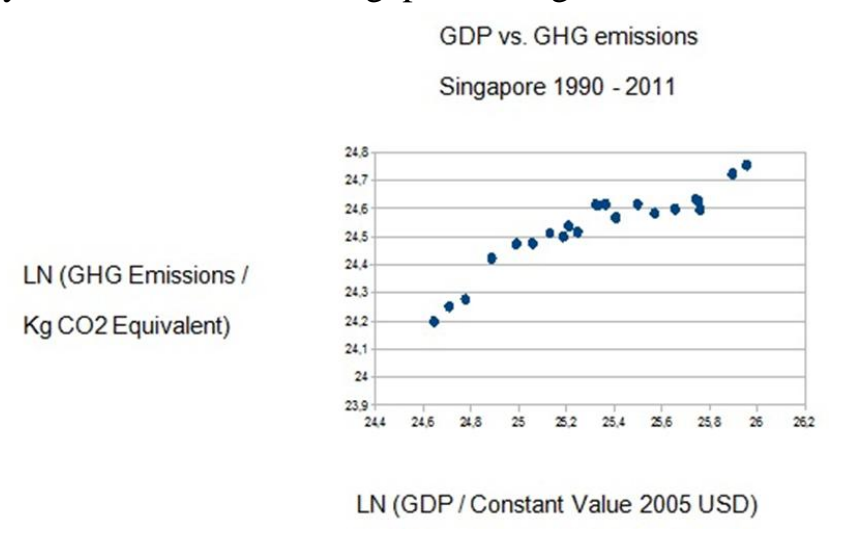

Figure27. SINGAPORE: LN (GHG / Kg CO2 eq and LN (GDP / Constant Value 2005 USD) 
Despite its official statements about being a GREEN city, emissions have been going up steadily in Singapore. The GHG:s is very high if related to per capita. Its energy mix is only oil and natural gas, imported from abroad (Figure 28). Singapore needs lots of electricity to bolster its advanced life style (air conditioning, total waste water cleaning, etc).

\section{Energy consumption in Singapore \\ By end-use}
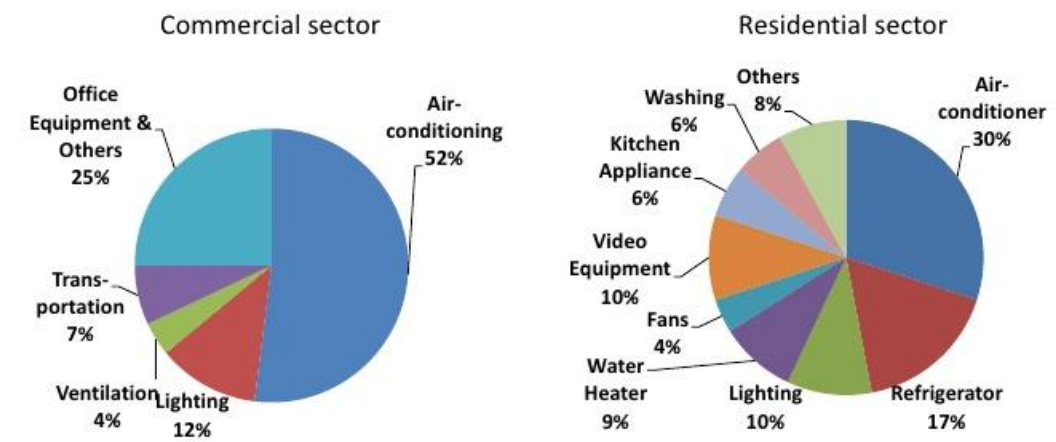

Major usage:

1. Air conditioning/ Refrigerator

2. Lighting

Source: Office Building Energy Saving Potential in Singapore, Cui Qi, 2006; E² Singapore, NEA, 2010

\section{Figure28}

Why would this island state need too much energy, resulting in such an amount of emission of GHG:s? Reply: the need for fossil fuels to generate electricity and make transportation possible. Singapore has a hot climate and handles that with a complete use of air conditioners all over the pkace. It is also a huge hub for shipping and air travel. It is impossible to generate so much electricity without emissions when using fossils fuels. Singapore has a large oil refinery.

Consider now another GREEN state, the United Arab Emirates (Figure 29).

GDP - GHG for UAE 1990 - 2011

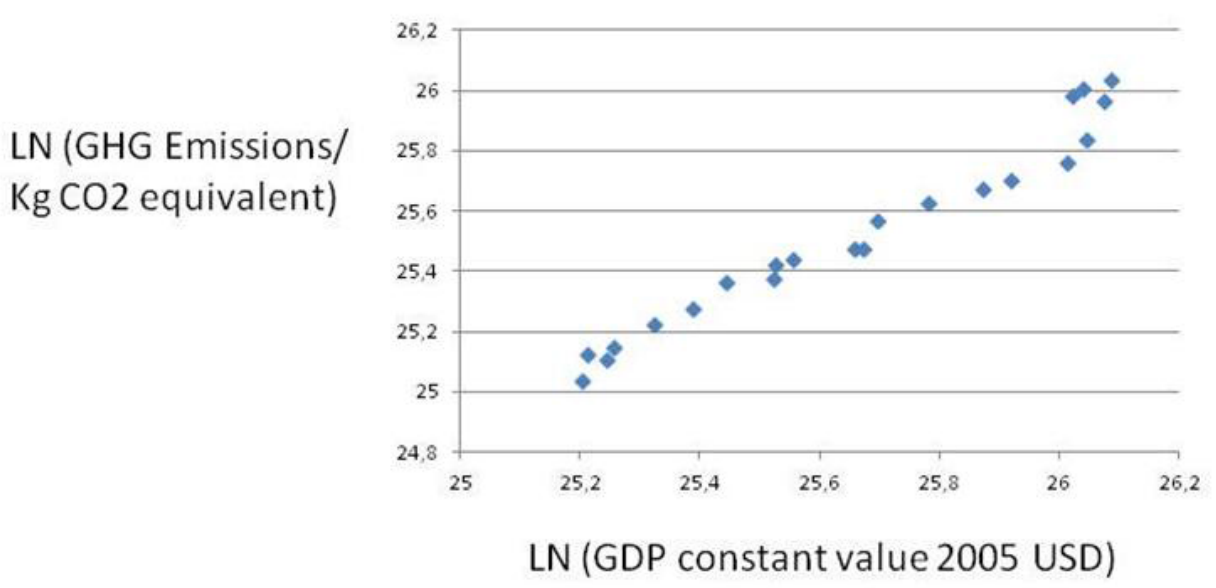

Figure29. UNITED ARAB EMIRATES: LN (GHG / Kg CO2 eq and LN (GDP / Constant Value 2005 USD)

The UAE have increased their emission of GHG sharply in relation the positive economic development of these emirates. They rely upon the fossil fuels of Abu Dhabi with immense oil resources. Like other Gulf States, the UAE boosts with building entirely GREEN sites, with energy from solar power and almost no waste. But it is based upon their enormous consumption of electricity generated out of burning oil and gas (Figure 30). The Gulf countries use lots of petrol, gas and electricity to uphold a stunningly high standard of living, which also results in extremely high levels of emissions per capita. 


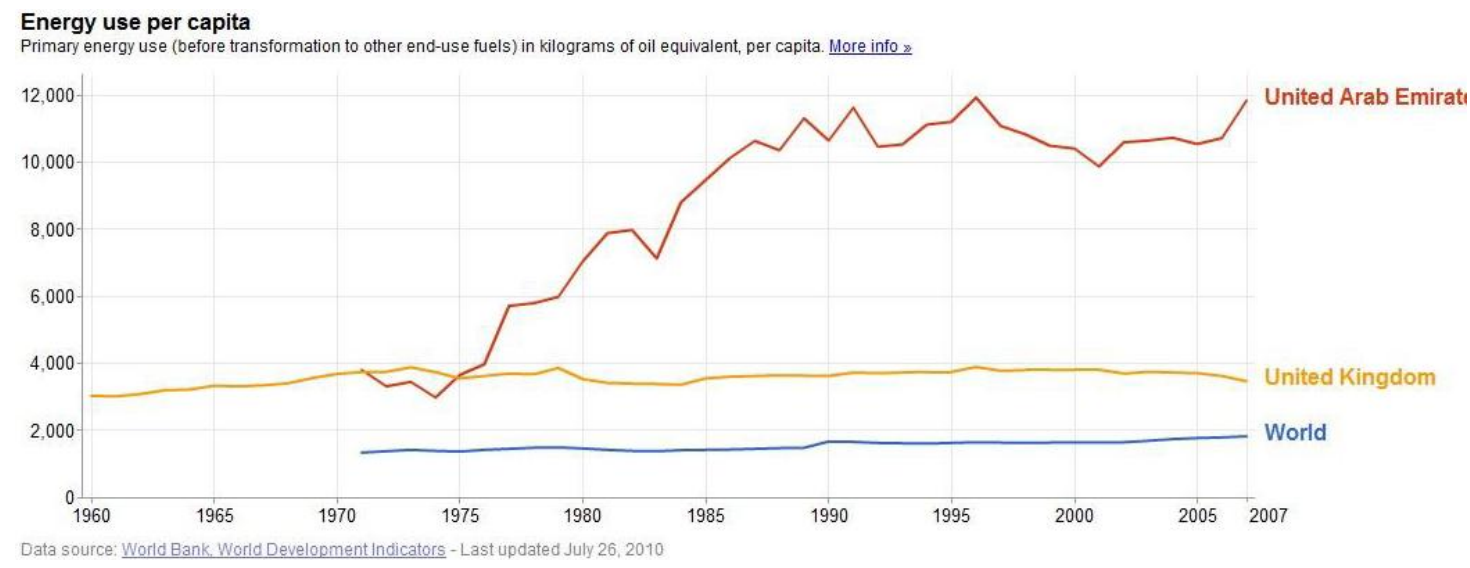

Figure30

In reality, the emissions per person are nowhere as high as in these super rich oil and gas emirates: UEL, Kuwait, Qatar and of course the Kingdom of Saudi Arabia. And they use enormous amounts of cement for paranoiac buildings, like especially Dubai and Abu Dhabi.

\section{Summing Up}

The standard image of a close link between GDP and emissions is much corroborated for the so-called super rich GREEN states. And they contribute a lot to the global emissions from air transportation that totally equals that of the worst emitters. As a matter of fact, both air and sea transportation pollutes very much in terms of $\mathrm{CO} 2$ :s. And the Gulf wants to be the flying hub of the globe.

\section{Planning, Projections and Predictions}

Decarbonisation calls for the world economies in a wide sense to change their energy consumption patterns. Either energy consumption must be cut back, or there should be an enormous transformation to carbon neutral energy sources, like wind, solar and atomic power. This happens in several countries in the advanced economies, but the scale is entirely insufficient, where in addition atomic power is often reduced in usage. In the Third World, traditional renewables are much resorted, and they are certainly not carbon neutral. The forests of Sudan are exploited illegally for exporting charcoal to Kenya, for instance.

Now, the energy planning by the big companies and international agencies tell about a completely different scenario for the future. Consider standard predictions in Figure 31.

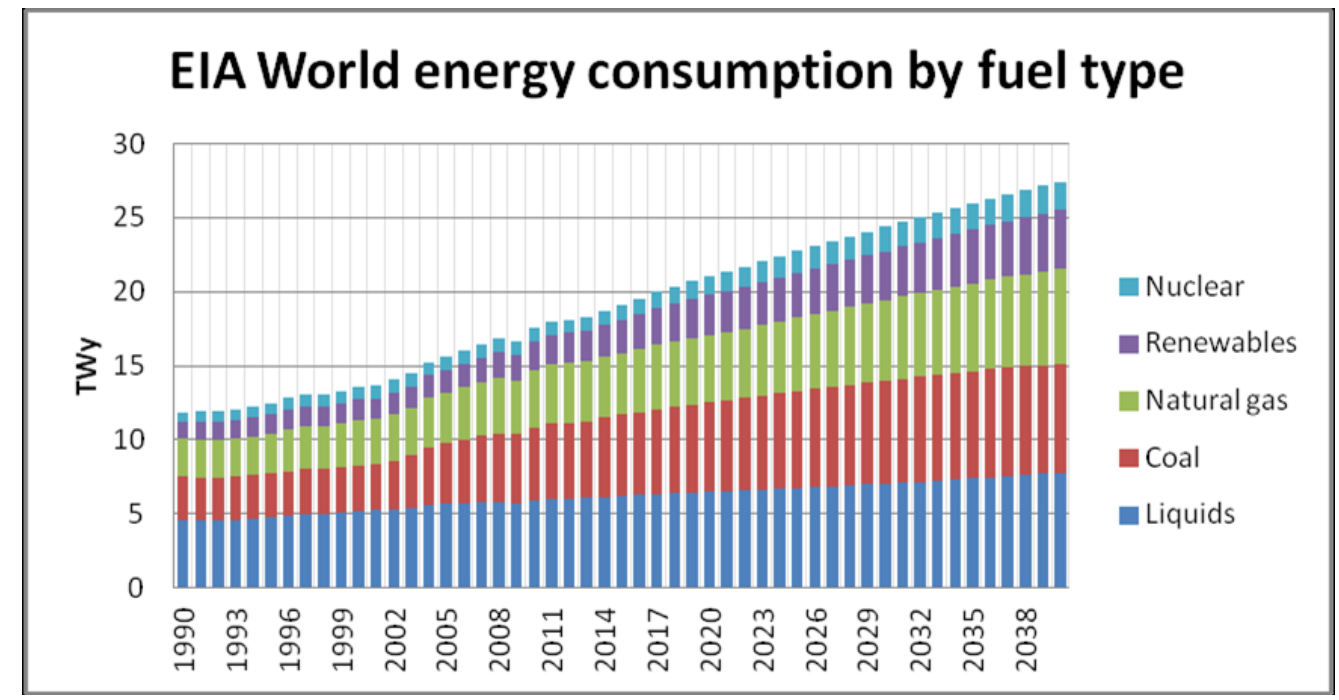

Figure31

These projections by Energy Information Administration (Washington, DC) are so far away from the COP21 project that the world seems on course to a global contradiction of major proportion.

It is the growth hungry Asian economies that lead the surge for a doubling of energy consumption (Figure 32). 


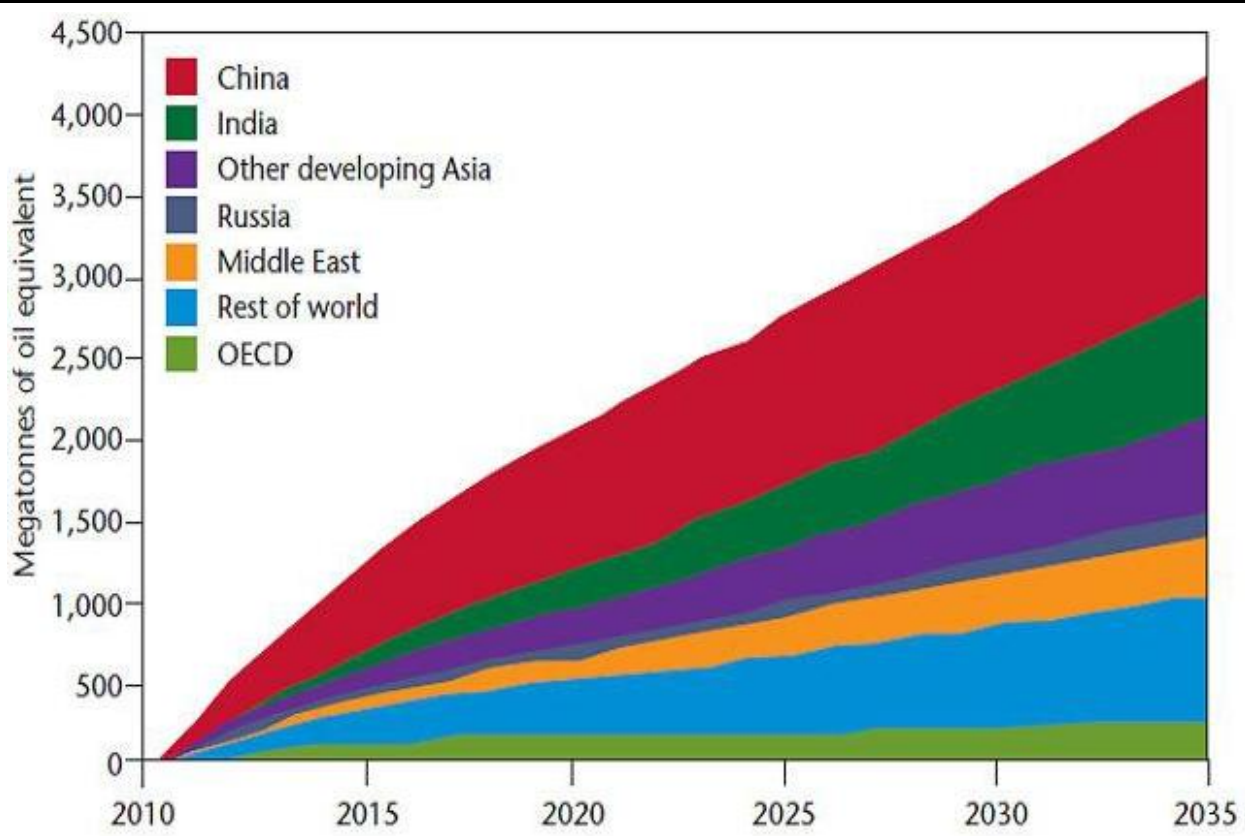

Figure32

Source. IEA: World Energy Outlook 2012

In these scenarios, global warming will become so strong it prevents further economic progress. Beyond, some 4 degrees plus human beings are hurt by climate change.

\section{Conclusion}

As the signs of global warming effects multiply, one must take into account the social sciences' lessons about the difficulty of policy implementation (Pressmann and Wildavsky, 1973, 1984). The COP approach may be too slow and too decentralised. In any case, it will be conducive to transactions costs, as countries quarrel about the changes that they must carry through. When energy transformation is too costly, countries will simply renege. The international secretariat of COP21 will not have control over country policies and their outcomes. There will be lots of asymmetric information, as governments engage in opportunistic behaviour with guile. The standard energy projections are completely out of touch with the climate change problematic. Economic development theory has yet to integrate the implications of COP21 into their main theoretical framework (see Literature below).

The coming politics of the implementation of COP21 Agreement fits well with standard models in game theory. Countries will attempt "free riding" when they face difficulties or the costs involved are too high. Thus small countries will play the N-1 game ad big countries will play the $1 / \mathrm{N}$ game: both types of countries reneging. Third world countries will be extremely dependent upon the Super Fund. But how is such a massive amount of money to be raised?

\section{SOURCES}

\section{GDP:}

World Bank national accounts data - data.worldbank.org

OECD National Accounts data files

\section{GHG:}

World Resources Institute CAIT Climate Data Explorer - cait.wri.org

EU Joint Research Centre Emission Database for Global Atmospheric

Research - http://edgar.jrc.ec.europa.eu/overview.php

UN Framework Convention on Climate Change -

http://unfccc.int/ghg_data/ghg_data_unfccc/time_series_annex_i/items/3814.php 
Sachs, J. (August 10th, 2015) "Sustainable Development for Humanity's Future" (http://jeffsachs.org/ 2015/08/sustainable-development-for-humanitys-future/)

International Energy Agency (IEA). Paris.

Energy Information Administration (EIA). Washington, DC.

Trends in Global CO2 Emissions - 2015 Report. The Hague: Netherland's Environmental Assessment Agency.

\section{LITERATURE}

Akpan, G. E. (2012). Electricity consumption. Carbon Emissions and Economic Growth in Nigeria, 2(4), 292-306.

Alam, M. J., Begum, I. A., Buysse, J., Rahman, S., \& Van Huylenbroeck, G. (2011). Dynamic modeling of causal relationship between energy consumption, $\mathrm{CO} 2$ emissions and economic growth in India. Renewable and Sustainable Energy Reviews, 15(6), 3243-3251.

Alkhathlan, K., \& Javid, M. (2013). Energy consumption, carbon emissions and economic growth in Saudi Arabia: An aggregate and disaggregate analysis. Energy Policy, 62(2013), 1525-1532.

Ang, J. B. (2008). Economic development, pollutant emissions and energy consumption Malaysia. Journal of Policy Modeling, 30(2), 271-278.

Arouri, M. E. H., Ben Youssef, A., M'henni, H., \& Rault, C. (2012). Energy consumption, economic growth and CO2 emissions in Middle East and North African countries. Energy Policy, 45(2012), 342-349.

Bloch, H., Rafiq, S., \& Salim, R. (2012). Coal consumption, CO2 emission and economic growth in China: Empirical evidence and policy responses. Energy Economics, 34(2), 518-528.

Halicioglu, F. (2009). An econometric study of CO2 emissions, energy consumption, income and foreign trade in Turkey. Energy Policy, 37(3), 1156-1164.

Jahangir Alam, M., Ara Begum, I., Buysse, J., \& Van Huylenbroeck, G. (2012). Energy consumption, carbon emissions and economic growth nexus in Bangladesh: Cointegration and dynamic causality analysis. Energy Policy, 45(2012), 217-225.

Kaygusuz, K. (2009). Energy and environmental issues relating to greenhouse gas emissions for sustainable development in Turkey. Renewable and Sustainable Energy Reviews, 13(1), 253-270.

Khan, M. A., Khan, M. Z., Zaman, K., Khan, M. M., \& Zahoor, H. (2013). Causal links between greenhouse gas emissions, economic growth and energy consumption in Pakistan: A fatal disorder of society. Renewable and Sustainable Energy Reviews, 25(2013), 166-176.

Kraft, J., \& Kraft, A. (1978). On the relationship between energy and GNP. Journal of Energy and Development, 3(2), 401-403.

Lotfalipour, M. R., Falahi, M. A., \& Ashena, M. (2010). Economic growth, CO2 emissions, and fossil fuels consumption in Iran. Energy, 35(12), 5115-5120.

Menyah, K., \& Wolde-Rufael, Y. (2010). Energy consumption, pollutant emissions and economic growth in South Africa. Energy Economics, 32(6), 1374-1382.

Ozturk, I., \& Acaravci, A. (2010). CO2 emissions, energy consumption and economic growth in Turkey. Renewable and Sustainable Energy Reviews, 14(9), 3220-3225.

PACJA (Pan African Climate Justice Alliance). (2009). The economic cost of climate change in Africa.

Pressman, J. and A. Wildavsky (1973, 1984) Implementation. Berkeley: Univ of Cal: Berkeley.

Soytas, U., Sari, R., \& Ewing, B. T. (2007). Energy consumption, income, and carbon Emissions in the United States. Ecological Economics, 62(3), 482-489.

Stern, N. (2007) Economics of Climate Change. Oxford: OUP.

Wolde-Rufael, Y. (2006). Electricity consumption and economic growth: A time series experience for 17 African countries. Energy Policy, 34(10), 1106-1114.

Xepapadeas, A. (2005). Economic growth and the environment. In K. G. Maler, J. R. Vincent (Eds.), Handbook of environmental economics (Vol. 3, pp. 1219-1271).

Zhang, X.-P., \& Cheng, X.-M. (2009). Energy consumption, carbon emissions, and economic growth in China. Ecological Economics, 68(10), 2706-2712. 
Appendix 1.Source: IPCC (2014); based on global emissions from 2010. Details about the sources included in these estimates can be found in the Contribution of Working Group III to the Fifth Assessment Report of the Intergovernmental Panel on Climate Change.

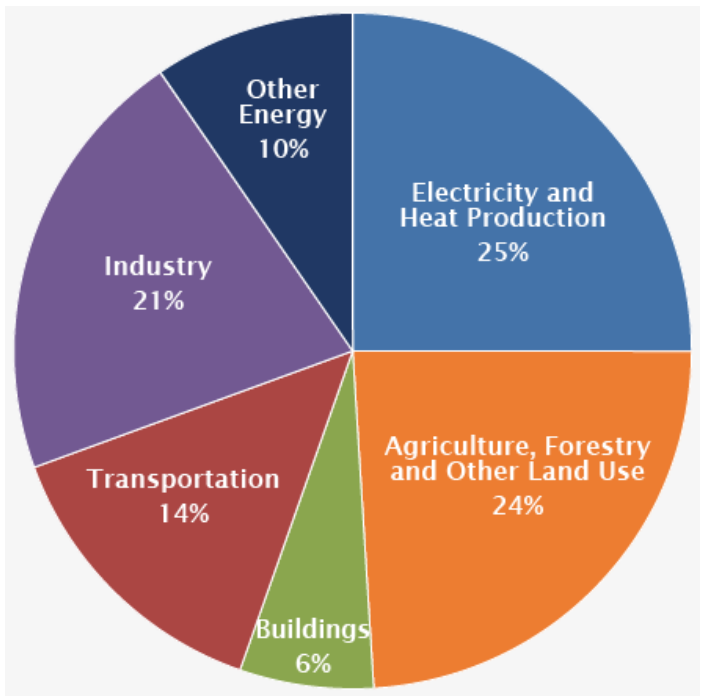

